NASA/TM-2004-212912

\title{
Systems Characterization of Combustor Instabilities With Controls Design Emphasis
}

George Kopasakis

Glenn Research Center, Cleveland, Ohio 
Since its founding, NASA has been dedicated to the advancement of aeronautics and space science. The NASA Scientific and Technical Information (STI) Program Office plays a key part in helping NASA maintain this important role.

The NASA STI Program Office is operated by Langley Research Center, the Lead Center for NASA's scientific and technical information. The NASA STI Program Office provides access to the NASA STI Database, the largest collection of aeronautical and space science STI in the world. The Program Office is also NASA's institutional mechanism for disseminating the results of its research and development activities. These results are published by NASA in the NASA STI Report Series, which includes the following report types:

- $\quad$ TECHNICAL PUBLICATION. Reports of completed research or a major significant phase of research that present the results of NASA programs and include extensive data or theoretical analysis. Includes compilations of significant scientific and technical data and information deemed to be of continuing reference value. NASA's counterpart of peerreviewed formal professional papers but has less stringent limitations on manuscript length and extent of graphic presentations.

- TECHNICAL MEMORANDUM. Scientific and technical findings that are preliminary or of specialized interest, e.g., quick release reports, working papers, and bibliographies that contain minimal annotation. Does not contain extensive analysis.

- CONTRACTOR REPORT. Scientific and technical findings by NASA-sponsored contractors and grantees.
- CONFERENCE PUBLICATION. Collected papers from scientific and technical conferences, symposia, seminars, or other meetings sponsored or cosponsored by NASA.

- SPECIAL PUBLICATION. Scientific, technical, or historical information from NASA programs, projects, and missions, often concerned with subjects having substantial public interest.

- TECHNICAL TRANSLATION. Englishlanguage translations of foreign scientific and technical material pertinent to NASA's mission.

Specialized services that complement the STI Program Office's diverse offerings include creating custom thesauri, building customized databases, organizing and publishing research results ... even providing videos.

For more information about the NASA STI Program Office, see the following:

- Access the NASA STI Program Home Page at http://www.sti.nasa.gov

- E-mail your question via the Internet to help@sti.nasa.gov

- Fax your question to the NASA Access Help Desk at 301-621-0134

- Telephone the NASA Access Help Desk at 301-621-0390

- Write to:

NASA Access Help Desk

NASA Center for AeroSpace Information 7121 Standard Drive

Hanover, MD 21076 
NASA/TM-2004-212912

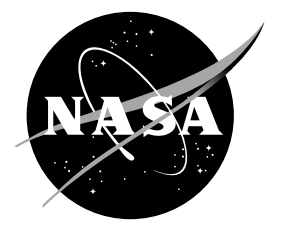

\section{Systems Characterization of Combustor Instabilities With Controls Design Emphasis}

George Kopasakis

Glenn Research Center, Cleveland, Ohio

Prepared for the

42nd Aerospace Sciences Meeting and Exhibit

sponsored by the American Institute of Aeronautics and Astronautics

Reno, Nevada, January 5-8, 2004

National Aeronautics and

Space Administration

Glenn Research Center 
This work was sponsored by the Low Emissions Alternative Power Project of the Vehicle Systems Program at the NASA Glenn Research Center.

Available from

NASA Center for Aerospace Information 7121 Standard Drive

Hanover, MD 21076
National Technical Information Service 5285 Port Royal Road Springfield, VA 22100

Available electronically at http:/ /gltrs.grc.nasa.gov 


\title{
SYSTEMS CHARACTERIZATION OF COMBUSTOR INSTABILITIES WITH CONTROLS DESIGN EMPHASIS
}

\author{
George Kopasakis* \\ National Aeronautics and Space Administration \\ Glenn Research Center \\ Cleveland, Ohio 44135
}

\begin{abstract}
$\underline{\text { ABSTRACT }}$
This effort performed test data analysis in order to characterize the general behavior of combustor instabilities with emphasis on controls design. The analysis is performed on data obtained from two configurations of a laboratory combustor rig and from a developmental aero-engine combustor. The study has characterized several dynamic behaviors associated with combustor instabilities. These are: frequency and phase randomness, amplitude modulations, net random phase walks, random noise, exponential growth and intraharmonic couplings. Finally, the very cause of combustor instabilities was explored and it could be attributed to a more general source-load type impedance interaction that includes the thermo-acoustic coupling. Performing these characterizations on different combustors allows for more accurate identification of the cause of these phenomena and their effect on instability.
\end{abstract}

\section{INTRODUCTION}

Lean-burning, low emission combustors are being investigated for aircraft gas turbine engines for the purpose of NOx reduction, better turbine temperature distribution and efficiency. These types of combustors, however, are more susceptible to thermo-acoustic instabilities. It has been widely accepted that these instabilities typically result from the coupling of the fluctuating heat release ${ }^{1}$ of the combustion process with the lightly damped acoustics of the combustion chamber. Dynamic analysis conducted here would tend to indicate that this type of coupling is only a part of a more general dynamic behavior that gives rise to combustor instability. This more generalized dynamic behavior involves source-load type impedance interactions, or other type of dynamic interactions involving characteristic equations.
Up until now, there have been some limited attempts to characterize the behavior of combustor instabilities for control design. In Ref. 2 the characterization presented covers instability phase and frequency randomness and net phase walks. In Ref. 3 the exponential growth behavior of the instability is shown at the moment the controller is turned off. These and other observed behaviors of the instability such as amplitude modulation, intra-harmonic couplings and random noise causing inherent unstable transitions during control will be discussed here.

For this effort, analyses and comparisons are performed on data from three different combustors consisting of a High Frequency combustor Rig Configuration (HFRC), a Low Frequency Rig Configuration (LFRC) and an actual Aero-Engine (AE). The AE data was supplied courtesy of Pratt \& Whitney (PW).

Many of the instability characteristics discussed in this paper were taken into account in the design and testing on a combustor rig ${ }^{4,5}$ of an adaptive phase shifting control approach ${ }^{6,7}$. Detailed characterization of combustor instabilities and the understanding of the coupling mechanisms are important for the design of active control as well as combustor components to avoid potentially adverse dynamic interactions.

The paper will present a description of the combustor rigs for the LFRC and the HFRC, followed by test results for the mentioned three combustor cases, and analysis characterizing the various instability behaviors. Finally, dynamic coupling analysis is presented that explains the possible cause(s) that give rise to combustor instabilities.

*Member AIAA. 


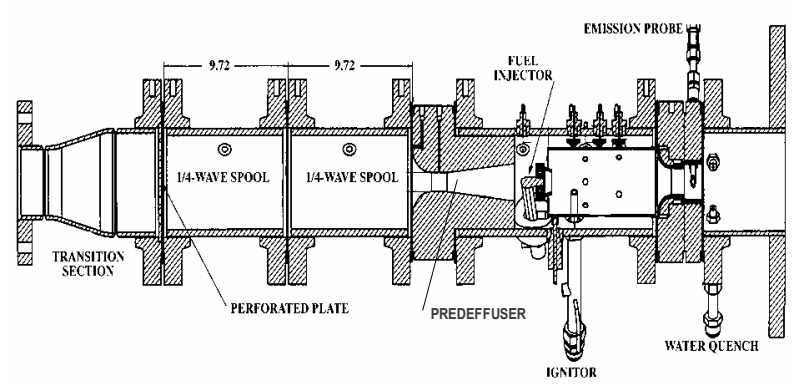

Figure 1 - Test Rig Configuration Apparatus

\section{COMBUSTION INSTABILITY RIG}

In order to focus control development toward realistic combustion instabilities, a combustor rig was developed to replicate an actual engine combustion instability. The sample problem selected for this rig is a combustion instability that was observed during the development of a high-performance aircraft gas-turbine engine. The frequency of the observed instability was $525 \mathrm{~Hz}$ and the magnitude of the pressure oscillations was sufficient to cause unacceptable vibratory stresses in the turbine.

The rig successfully replicates the engine instability and operates at engine pressure and temperature conditions. This single-nozzle combustor rig has many of the complexities of a real engine combustor including an actual engine fuel nozzle and swirler, dilution cooling, and an effusion-cooled liner. The rig was operated at pressures, temperatures, and fuel-air ratios corresponding to three different engine operating conditions. Figure 1 shows the test rig apparatus for the $533 \mathrm{~Hz}$, high frequency configuration. For the conditions corresponding to a mid-power level chosen for control evaluation $\left(T_{3}=770{ }^{\circ} \mathrm{F}, P_{3}=200\right.$ psia, fuel-air ratio $=$ 0.03 ) test results established the existence of a

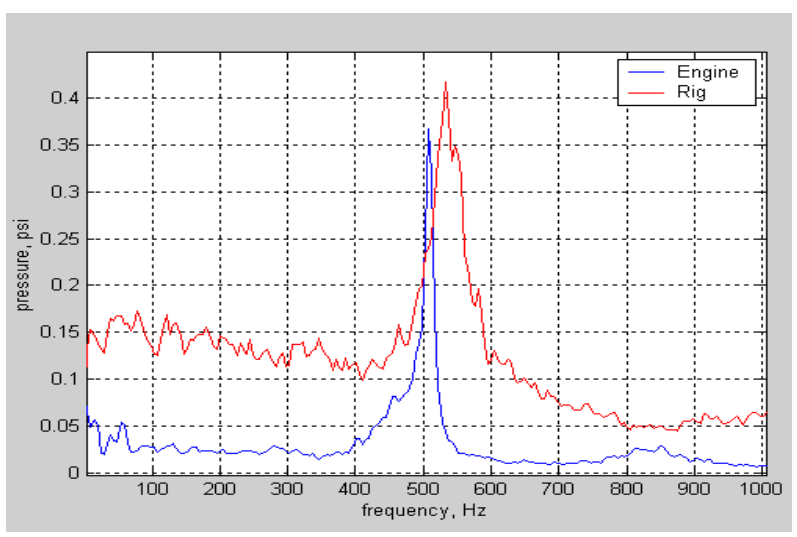

Figure 2 - Comparison of AE and HFRC Combustor Amplitude Pressure Spectra

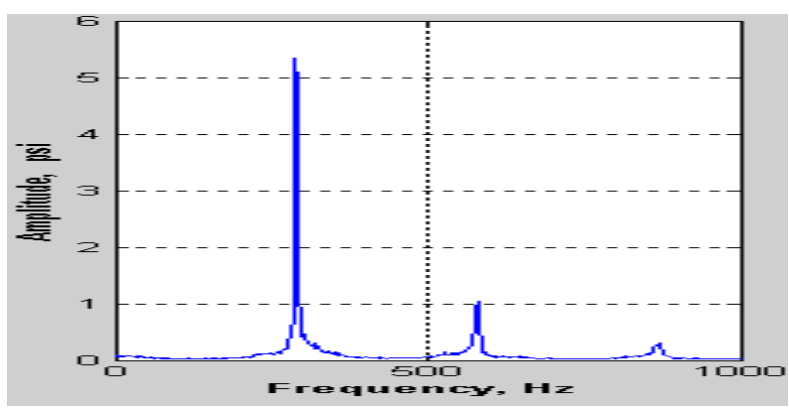

Figure 3 - Pressure Spectra in LFRC

combustion instability at approximately $533 \mathrm{~Hz}$. A comparison between the pressure amplitude spectra in the $\mathrm{AE}$ and in the HFRC at comparable operating conditions is shown in Figure 2. The spectrum for the LFRC is shown in Figure 3. The LFRC is obtained by placing the pre-diffuser section in Figure 1 before the two $1 / 4$ wave spool section, which has the effect of elongating the active acoustic length by approximately 19 in. This geometry exhibits an instability at $\approx 290 \mathrm{~Hz}$.

The research combustor rig was developed in partnership with Pratt \& Whitney and UTRC.

\section{COMBUSTION INSTABILITY CHARACTERIZATION}

In this section results will be presented characterizing the combustor instability of the HFRC and LFRC as well as the instability observed in the developmental AE. Data and analysis comparisons are performed with the idea of providing a more in-depth understanding of the instability behaviors and the underlying dynamic processes to be used in control developments design and possibly combustor components design. Frequency sweep data that would normally be used for transfer function development for the purpose of modeling and control design were not available for this study. In this section the three combustor configurations will be compared in an attempt to characterize the instability for frequency randomness, amplitude modulation, net random phase walks, exponential growth and intra-harmonic couplings. Another challenge of combustor instability control is the inherently unstable system that results when the instability is being controlled and suppressed down near the wideband noise level. Also, the combustor wide-band random noise, which severely limits the achievable amount of instability suppression, will be discussed and some relations will be derived to show the mechanisms of noise and its impact on controls design. In addition, a possible cause of combustor instability will be discussed such as source-load impedance interactions or interactions due to other characteristic type couplings. 


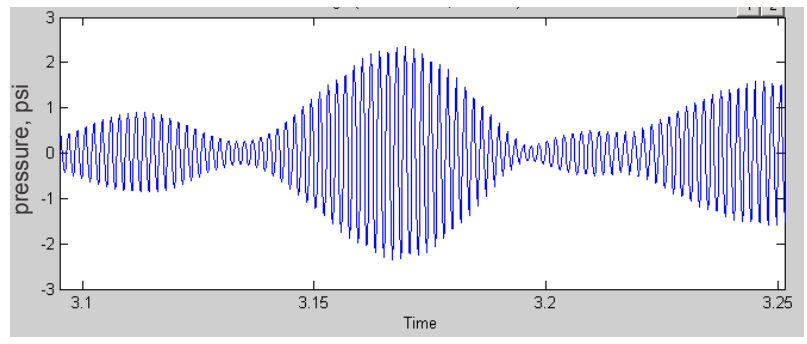

Figure 4 - Open Loop Filtered Instability Pressure of High Frequency Rig Configuration

Frequency Randomness

For the data examined, the combustor instability is not a pure tone, but rather it exhibits frequency randomness centered on a dominant frequency. The center frequency depends primarily on the combustor geometry, the speed of sound in the combustion mixture, as well as various impedance dynamics and other characteristic couplings. In Figure 2 and Figure 3 the differences in the randomness of the instability frequency is indirectly evident by the different sharpness of the respective instability peak. Frequency randomness is less with the LFRC, which has a higher signal-to-noise ratio, followed by the AE and next by the HFRC. Some of the effect perceived as frequency randomness is due to the fact that the instability constantly undergoes phase change as in a random net phase walk, which will be discussed later. The frequency randomness is approximately $\pm 3 \mathrm{~Hz}, \pm 10 \mathrm{~Hz}$ and $\pm 35 \mathrm{~Hz}$ for the LFRC, the $\mathrm{AE}$ and the $\mathrm{HFRC}$, respectively. The higher the signal-to-noise ratio, the more coherent the instability becomes, and therefore, the lesser the frequency randomness.

From a controls perspective and whether an observer or a band-pass filter is used to isolate the instability, this frequency randomness should not have a significant impact. This is true provided the filter pass band covers the frequency uncertainty range. The operation of the engine may shift the instability frequency much more than this typical frequency randomness.

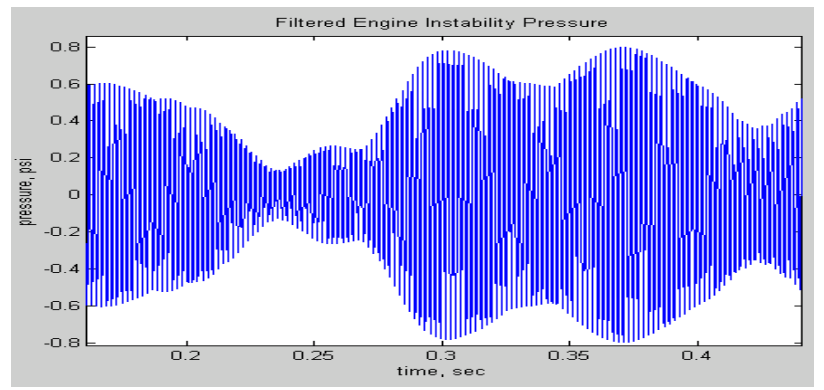

Figure 5 - Open Loop Filtered Instability Pressure of Engine

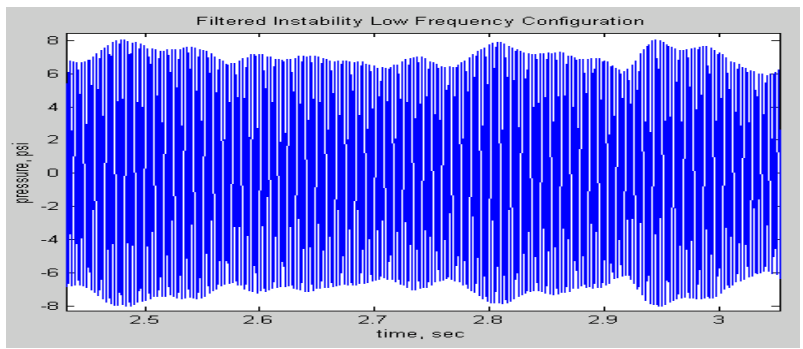

Figure 6 - Open Loop Filtered Instability Pressure of Low Frequency Rig Configuration

Amplitude Modulation

Typical instability pressure waveforms from the three combustor configurations were band-pass filtered (with $\sim 10 \mathrm{~Hz}$ pass-band) to remove the wideband noise in order to study trends in amplitude modulation. Figure 4 , Figure 5 and Figure 6 show typical time slices of the filtered instabilities. Amplitude modulation is evident in all test data. The amplitude modulations of the instability are more severe in the case of the HFRC, followed by the $\mathrm{AE}$ and next the LFRC. As with frequency randomness, amplitude modulation of the instability is more pronounced when the signal-to-noise ratio is low. Therefore, the data suggests that amplitude modulation of the instability depends on the noise level. For comparison, the narrow- band signal-to-noise ratio for the pressure amplitude spectra density, shown in Figure 2 and Figure 3, are in the order of 100, 14 and 3 for the LFRC, the HFRC and the AE, respectively. In the time domain, not shown here, the wideband signal-to-noise ratio for the HFRC is approximately 0.15 ; that is the instantaneous noise amplitude is approximately 7 times that of the instability signal. By comparing typical time domain slices of the instability in Figure 4 and Figure 5, another interesting observation is that the peak amplitude of the AE instability is significantly less than that of the HFRC. This is the case even though the peak pressure amplitude spectra of these two instabilities are about the same, according to Figure 2. The difference seems to be the noise level, which is significantly higher with the HFRC, causing appreciably higher amplitude modulations with this combustor. This makes the peak time domain amplitudes of the AE and the HFRC when the noise is included (not shown here) $\sim 2$ and 5 psi, respectively. The conclusion is that wideband noise seems to be the primary driver for amplitude modulations.

Each filtered instability waveform was normalized with respect to its maximum amplitude before constructing the pressure Probability Density Functions (PDF's), in Figure 7 for more direct comparisons of the severity in amplitude modulations. As shown in this figure, the instability of the LFRC more closely approximates the reference sine wave of constant 


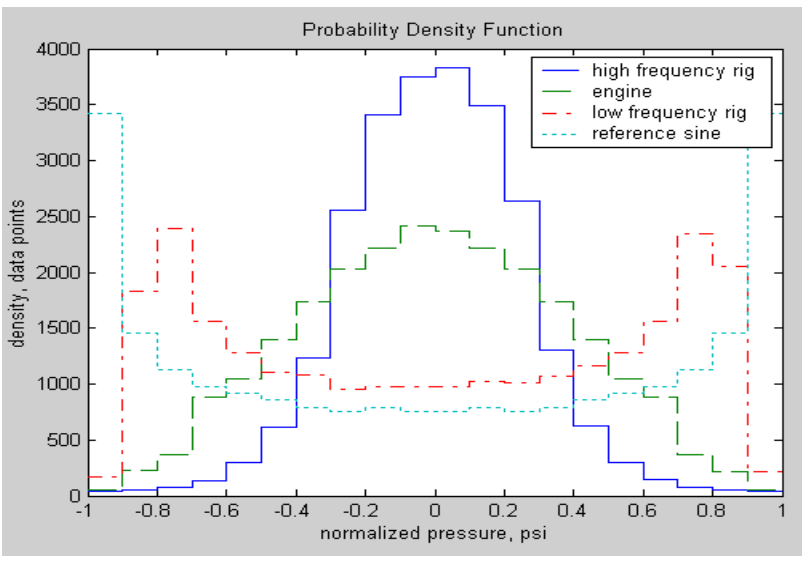

Figure 7 - Comparison of Probability Density Functions of Combustor Instabilities and Reference n $\cdots$ amplitude, while the HFRC exhibits the least of the constant-amplitude sinusoidal behavior.

It has been observed that amplitude modulations under active control become increasingly severe as the instability is suppressed. The more the instability is suppressed the less the signal-to-noise ratio becomes. Therefore, this follows the same logic that amplitude modulations are dependant on the instability signal-tonoise ratio. Obviously, this means that the further the instability is suppressed the more difficult it becomes to control. As will be discussed later, this difficulty is compounded by the observation that in some control designs successful instability suppression results in an inherently unstable controller. Furthermore, it is observed that as the instability is suppressed there is the coupling effect between amplitude modulations and large dead time phase delay. This effect results in large fluctuations of the equivalent controller proportional gain. The phase delay estimated for the HFRC is $\sim 1400^{\circ}$ and the phase delay calculated with the LFRC using frequency response data was $\sim 760^{\circ}$. The severity in amplitude modulation of the less establish instabilities coupled with large phase delays, would indicate that it would be significantly more difficult to suppress an instability that is not well pronounced (small signal-tonoise ratio) as in the case of the HFRC. The time delay effect combined with amplitude modulations causes the effective DC control gain to vary appreciably. In Ref. 7 this variability in the effective control gain was countered by developing a control strategy called Discontinues Exponential Gain Modulation Control (DEGMC).

\section{Net Random Phase Walks}

Another important characteristic of the instability is its cycle-to-cycle phase change variability, and over longer time its net random phase walks. Phase change or phase walks are measured with respect to a constant

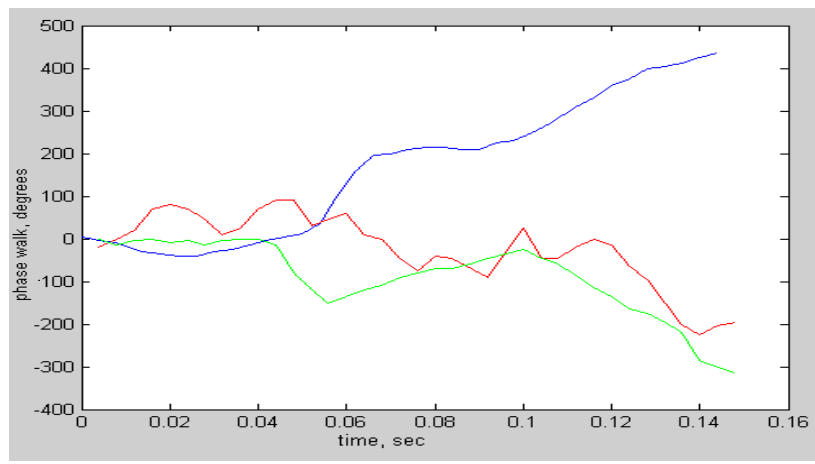

Figure 8 - Net Random Phase Walk of High Frequency Rig Instability

phase reference sine wave of the same frequency as the instability. Statistical analysis of cycle-to-cycle variability in combustor instabilities, which demonstrates a net random phase walk, is discussed in Ref. 2. The analysis performed here will attempt to compare these characteristics for different combustors and noise levels and establish trends useful for control design.

Three independent net random phase walks for each of the cases involving the HFRC, the AE and the LFRC are shown in Figure 8, Figure 9, and Figure 10, respectively. The random net phase walk observed in the data is consistent with the observations in Ref. 2. It can be seen that the HFRC, with the lower signal-to-noise ratio, produces the most severe net random phase walks. The phase walks for the HFRC amount to $\sim 450^{\circ}$ in $0.14 \mathrm{sec}$, or an average of $\sim 6^{\circ}$ per instability cycle of $\sim 530 \mathrm{~Hz}$, or an average of $\sim 80^{\circ}$ for a typical control cycle of $40 \mathrm{~Hz}$. At the worst case, the phase walk is about $400^{\circ}$ over the same control cycle. The AE instability, with less noise exhibits severe net random phase walks, but somewhat less than that of the high frequency rig. On the other hand, the more pronounced instability of the LFRC produced only one net random phase walk for all the data that were analyzed as shown in Figure 10. Furthermore, the phase walk with the LFRC is, at most, approximately $40^{\circ}$ per control cycle, which is an order of magnitude less than that of the HFRC.

The phase change is more severe when the amplitude of the modulation reaches near zero. This is shown in Figure 11 as hard minimum. At low instability amplitude the instantaneous signal-to-noise ratio becomes high, which means that the noise dominates the process during this time. Since the most severe phase change occurs when the noise dominates the process, it can be concluded that random noise is responsible for the phase walks. Comparing the phase walks of these three combustor cases, it can also be concluded that the 


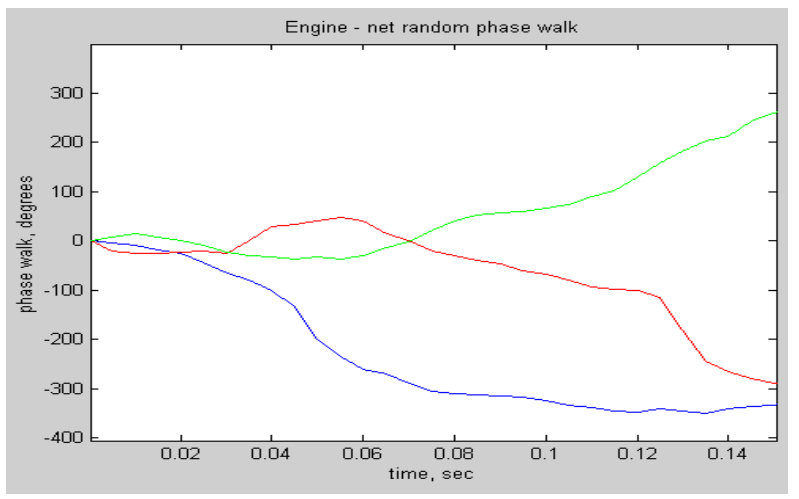

Figure 9 - Net Random Phase Walk of Engine Instability

severity of the phase walks is related to the signal-tonoise ratio of the instabilities.

Through simulation results, it has been observed that even when a pronounced instability is suppressed through feedback control, the phase randomness and phase walk become increasingly more severe. This result is to be expected, because the signal-to-noise ratio decreases as the instability is suppressed. Figure 12 shows the phase walks of the controlled instability in the HFRC using the controller described in Ref. 6 and 7. Of interest here is the observation that the controller seemed to eliminate the net phase walks and hold the phase randomness within a phase region of $180^{\circ}$ or less, occasionally undergoing $\sim 360^{\circ}$ phase slips. In some cases phase slips are initiated but are never completed. Phase slips have also been observed to go from $360^{\circ}$ to $720^{\circ}$. That, however, was just phase wrapping, not a phase walk. It seems that the controlled fuel modulation reduces the effect of the noise, especially when the instability amplitude is low compared to the wideband noise. So active control modulation seemed to cause the phase behaviors of the instability to be more organized; that is, with less randomness compared to the open-loop behavior.

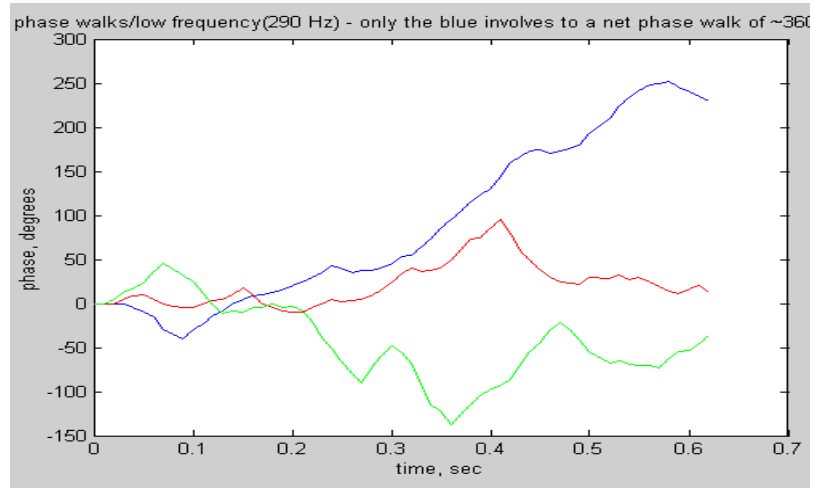

Figure 10 - Net Random Phase Walk of Low Frequency Rig Configuration

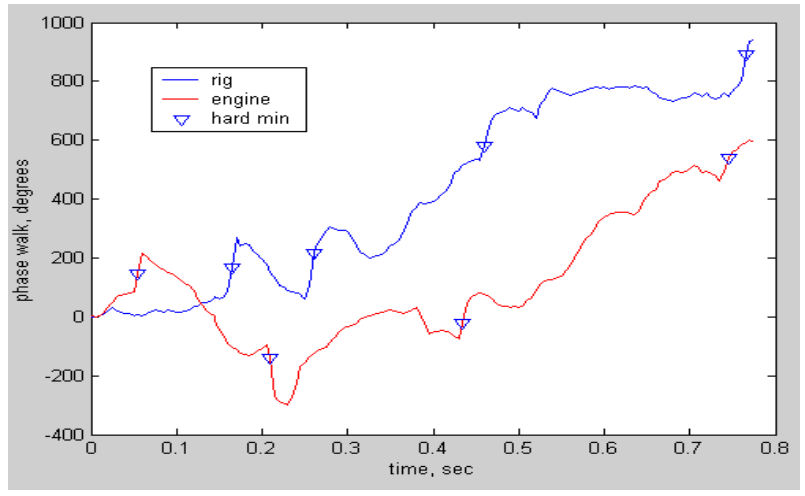

Figure 11 - Net Random Phase Walks Showing Severe Phase Change Associated With Low Amplitude Modulation

\section{Exponential Growth}

In simulations, it has been observed that at the onset of the combustor instability, or when the controller is turned off, the instability grows approximately exponentially starting from small amplitude and ending up at a final steady state amplitude (discounting the amplitude modulations for now). This is illustrated in Figure 13, which shows the self excited instability growing exponentially with time from a low value to a higher steady-state amplitude. This characteristic has also being observed in combustor tests ${ }^{7}$ and is consistent with the results in Ref. 3, which shows the instability growth in a Rijke tube experiment. The exponential rise with time of the instability is closely associated with the natural behavior of resonances.

In terms of controls design, an exponential growth characteristic of the instability points to the fact that the instability will grow quickly to uncontrolled levels if control tracking to suppress the instability is temporarily lost. This implies that the control logic must quickly sense loss of control tracking and then quickly reestablish control suppression if the desire is to maximize instability suppression. Again, loss of control

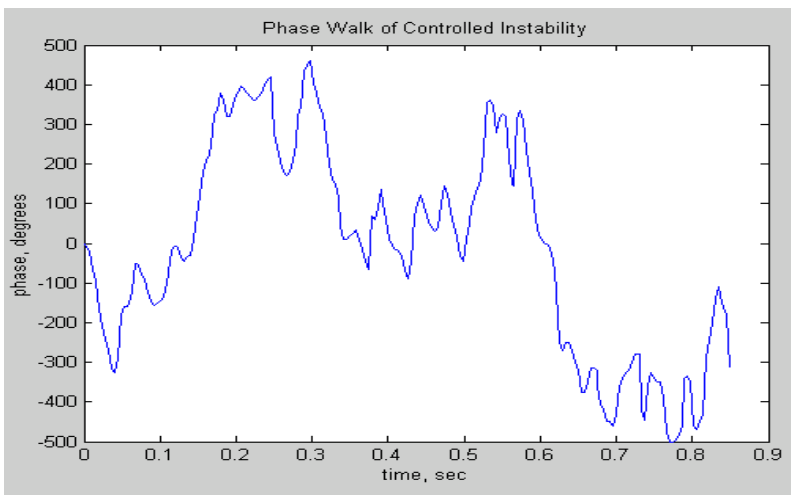

Figure 12 - Phase Walk of Controlled Instability 


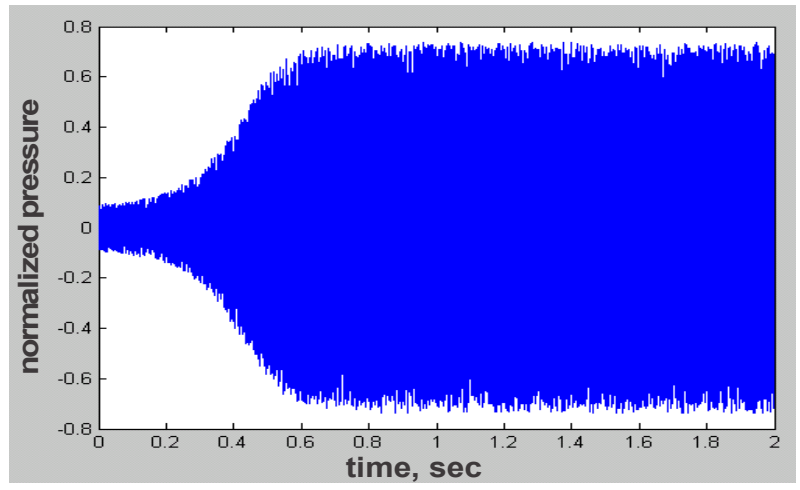

Figure 13 - Simulated Combustor Instability Unset Showing Exponential Growth

tracking is unavoidable at suppression levels near the noise level, where the system becomes inherently unstable.

\section{$\underline{\text { Intra-Harmonic Coupling }}$}

From time domain data comparing the controlled instability vs. the applied control signal ${ }^{7}$, it was reported that there is evidence of instability inertia or a selfreinforcing mechanism that couples the instability harmonics. It was reported that this effect was beyond the expected influence of the large dead-time phase delay of the plant. Indeed, such an intra-harmonic coupling or self-excitation within certain frequency components of the same signal would constitute a rare phenomenon in dynamic systems. To further investigate this effect individual harmonics were extracted from the original instability signal of the LFRC, and frequency shifted in order to analyze the coherence of these selected harmonics.

The original instability signal for the LFRC shown in Figure 3 was band pass filtered, with a filter centered at $290 \mathrm{~Hz}$, in order to generate a signal $y$ of the fundamental instability frequency of $\sim 290 \mathrm{~Hz}$. Then the original signal was resampled at $2.5 \mathrm{kHz}$, which is half the original sampling frequency of $5 \mathrm{kHz}$. The effect of this resampling was to halve all the frequency components of the original signal. Next, this signal containing the shifted frequencies was band-pass filtered with a center frequency of $290 \mathrm{~Hz}$ and with a sampling frequency of $2.5 \mathrm{kHz}$. The result is a signal $\mathrm{x}$ converted from 580 (second harmonic) to $290 \mathrm{~Hz}$. This signal frequency conversion maintains the amplitudes of the second harmonic of $\sim 580 \mathrm{~Hz}$ and preserves a consistent phase relation with the original signal. That is, if at some point in time the original signal has a phase $\theta$ from a chosen reference, the converted signal will have a phase $\theta+\phi$, where $\phi$ is the filter phase shift at that frequency. Based on this the magnitude squared coherence of signals $x$ and $y$ can be calculated as if these signal

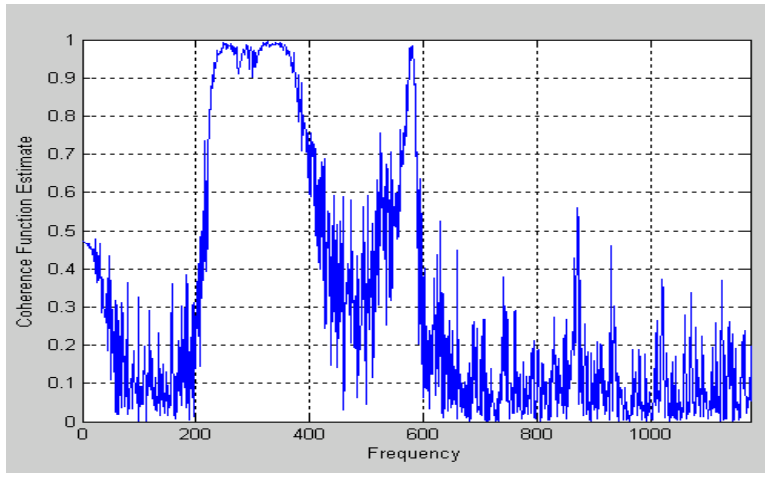

Figure 14 - Instability Harmonics Coherence Plot

components are the result of an input-output system relation:

$$
C_{x y}(f)=\frac{\left|P_{x y}(f)\right|^{2}}{P_{x x}(f) P_{y y}(f)}
$$

Where $P_{x x}, P_{y y}, P_{x y}$ are the power spectra of $x, y$ and the cross spectrum of $x$ and $y$, respectively. Each of these spectra is mathematically related to its correlation sequence by the discrete-time Fourier transform. The coherence in Equation 1 is plotted in Figure 14.

As can be seen in this figure the coherence between the second and the first harmonic is high (near one). The glitches shown near coherence of one are perhaps due to the differences of the band-pass filters (somewhat different bandwidths and attenuation properties). Also, coherence at the second harmonic (i.e. coherence between the second and fourth harmonic) is high. Because the band-pass filters were designed with a narrow pass-band around $290 \mathrm{~Hz}$, and sharply attenuate frequencies outside this pass-band, this result was not expected at first. This figure also shows that from approximately 240 to $360 \mathrm{~Hz}$ the coherence is high, which also corresponds to Figure 3 at the frequencies where pressure amplification is shown, above the noise floor. This will tend to indicate that the combustor dynamics are such that it tends to amplify noise at a region center around the instability frequency, and also that there exists some self-excitation mechanism between frequencies near the fundamental and frequencies near the second harmonic. These coherence results were obtained near the end of the analysis, but similarly it is expected that high coherence can be shown between other lower order harmonics (i.e. harmonics lower the Nyquist frequency: $1 / 2$ of the sampling frequency). It is expected that these results would also be applicable to the actual engine case.

The coherence suggests that additional suppression of the fundamental instability frequency may be possible 
by simultaneously controlling to suppress the higher order harmonics. Furthermore, selecting and controlling discrete frequencies in the neighborhood of the instability may further improve instability suppression.

\section{$\underline{\text { Effects of Combustor Noise in Instability Control Design }}$}

It was found through simulation and testing ${ }^{6,7}$ that noise is the primary factor limiting the degree to which the combustor instability can be suppressed. At suppression levels near the noise floor the control system becomes unstable (i.e. unstable in the sense that, any control applied at this point will cause amplification of the instability), thereby, limiting the amount of suppression possible. Such limitation posed by combustor noise is related to the large transport phase delay of the combustor process.

The transport phase delay for the LFRC was calculated to be about $760^{\circ}$, while that of the HFRC was estimated to be about $1400^{\circ}$. In either case, such large phase delays are far beyond the typical delays associated in so called non-minimum phase systems in controls design, which pose a severe design challenge. This large phase delay forces the control bandwidth to be quite low, in the order of several $\mathrm{Hz}$ to $10 \mathrm{~Hz}$ or so. For instance, in Refs. 6 and 7 the control updating cycle used for combustor instability control was $40 \mathrm{~Hz}$, which gives an idea about how low the control bandwidth is. Therefore, such a low control bandwidth will have no effect on the noise at the instability frequency (at several hundred $\mathrm{Hz}$ ).

In a classical feedback control system, where noise is summed at the output, the output-to-noise transfer function is

$$
\frac{c}{n}=\frac{1}{1+L_{C L}}
$$

where $L_{C L}$ is the closed loop gain of the system. From Equation 1 it can be seen that a properly designed controller can attenuate the wideband noise up to the $0 \mathrm{~dB}$ cross-over frequency of the closed loop gain.

In comparing the effectiveness of different control designs to suppress the instability, combustor instability with a difference of $\pm 100^{\circ}$ or so in transport phase delay will not appreciably impact the control design. Again, that is because the possible control bandwidth in the control design still remains considerably less than that of the instability frequency. Given this fact, the discriminator in comparing different control designs has to be noise. Therefore, in terms of amplitude spectral density, the following criteria should be a good metric for comparing control methodologies; the degree to which the instability is suppressed relative to the wide band noise. Based on this, it is repeated here what was introduced in Ref. 7 as the Instability Suppression Ratio (ISR):

$$
I S R^{-1}=\frac{S_{N}}{S_{I}}
$$

where $S_{N}$ is the average amplitude of the wide band noise spectra in the region of the instability, and $S_{I}$ is the peak amplitude spectra of the suppressed instability (provided that the controlled instability is discernibly less than the uncontrolled case). The interpretation of the average noise amplitude $S_{N}$, in cases where the wide band noise is not flat, would be the noise value at which the instability would be indistinguishable from the noise floor. Based on this definition, an $\mathrm{ISR}^{-1}$ of 1 would be the maximum

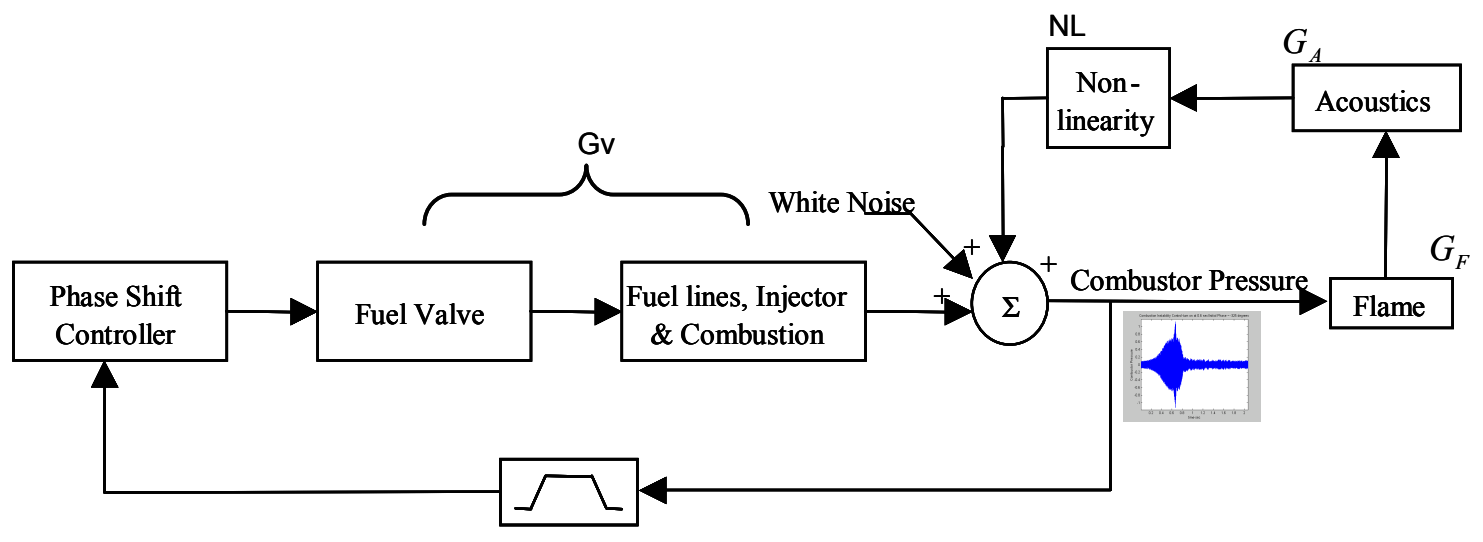

Filter

Figure 15 - Combustion Instability Control Block Diagram 
possible suppression achievable, in which case the instability will be indistinguishable from the noise on an amplitude spectral density plot.

The instability suppression control diagram used in $^{6,7}$ is repeated here in Figure 15. Based on this instability control diagram, the instability-to-noise transfer function (in pressure) is

$$
\frac{p}{n}=\frac{1}{1+G_{C} G_{V}+G_{F} G_{A}}
$$

and

$$
G_{C}=N(A, \omega)
$$

where $N(A, \omega)$ is the describing function of the controller with A being the amplitude and $\omega$ being the frequency (see Ref. 11 for an explanation on describing functions). In this case, as seen in Equation 4 the closed loop gain of the system is

$$
\begin{aligned}
& L_{C L}(s)=G_{C}(s) G_{V}(s) \\
& L_{S E}(s)=G_{F}(s) G_{A}(s)
\end{aligned}
$$

where $L_{C L}$ and $L_{S E}$ are the closed loop controlled gain and the open loop self excitation gain of the combustor system. Equation 4 is similar to the classical control structure of Equation 1, except in this case the noise attenuation also depends on the self excitation gain $L_{S E}$. Therefore, the noise attenuation in the combustor system also seems to depend on the designed, effective flame and acoustic dynamics, which effect the thermo-acoustic self-excitation. This could be the case perhaps because a pronounced instability can become more organized, and more effectively draw energy at the resonant frequency, thereby effectively reducing the surrounding noise. As described before, this control process has a low control bandwidth. Therefore, the closed loop gain in Equation 6 can have a significant impact on Equation 4 only in the low frequency range, and negligible contribution at higher frequencies, which includes the instability frequency as:

$$
\frac{p}{n} \cong \frac{1}{1+L_{S E}}, \quad \text { for } \quad f_{C} \prec f \leq f_{C R}
$$

where $f_{C}$ and $f_{C R}$ are the phase shift update frequency of the controller and the $0 \mathrm{~dB}$ cross-over frequency of the loop gain $L_{S E}$, respectively. Equation 8 says that the more pronounced the instability is (i.e. the higher the gain $L_{S E}$ ), the less the combustor pressure at this frequency range will be influenced by noise. This is supported by the studies presented here, where the LFRC is the least influenced by noise. Alternatively, Equation 8 says that a high self-excitation loop gain $L_{S E}$ attenuates noise. And for $\left|L_{S E}\right| \succ 1$ noise attenuation $n_{A}$ will be dominated by the gain of $L_{S E}$ and $n_{A}$ will be $\sim$ equal to the magnitude of this self excitation gain as:

$$
n_{A} \cong\left|L_{S E}\right|, \quad f_{C} \prec f \leq f_{C R} \&\left|L_{S E}\right| \succ 1
$$

Equation 8 can also be expressed in the limit sense as

$$
\lim _{\left|L_{S E}\right| \rightarrow 0} \frac{p}{n}=1
$$

This indicates that as $\left|L_{S E}\right| \rightarrow 0$, which is the case when the instability is being suppressed near the noise level, the combustor instability pressure is increasingly influenced by noise. In the limit as $\left|L_{S E}\right|=0$, the instability pressure has one-to-one correspondence to noise. These results are supported by experimental observations discussed earlier. Could it also be that combustors with a less pronounced instability will naturally have higher amplitudes of wideband noise, as seen with these 3 combustor cases analyzed here? Equation 8 seems to indicate that this may indeed be the case.

As discussed in this and previous sections wideband noise in combustors forms a lower bound on the level the instability can be suppressed. Based on this analysis, it seems that a pronounced instability, which may not be good for the engine offers more opportunity for control design (assuming the fuel valve has sufficient control authority) because wide band noise will be low. However, with increased suppression of the instability, noise may start to increase at some point which may limit the control effectiveness.

\section{$\underline{\text { Cause of Combustor Instability - Hypothesis }}$}

In most of the published works on combustor instability the cause of the instability is attributed to coupling between the heat release and the acoustics of the combustor chamber. In this section the possible causes of the observed combustor instability will be discussed from a systems dynamics perspective.

Normally, if combustor instability exists, the frequency is expected to be at the natural acoustic frequency of the surrounding volume (e.g.; resonance of a tube, the Helmholtz frequency, etc). However, it often 
turns out that the predicted and the actual instability frequencies in the combustor don't match. In the initial NASA-PW work, it was not exactly clear what factors determine the frequency of the combustor instability. Also, it was not clear why sometimes the frequency observed was sufficiently different than what would be expected from purely acoustic calculations. Initially the purpose of each $1 / 4$-wave spool shown in Figure 1, was to reinforce the original instability observed without the spools. However, the addition of each spool section resulted in shifting the instability to a lower frequency (i.e. $\sim 350 \mathrm{~Hz}$ and $290 \mathrm{~Hz}$, successively). In Ref. 8 the attempt was made to experimentally validate the timedelay theory; that is, a certain time-delay that will cause the heat release and the acoustic pressure to reinforce each other, thereby, giving rise to instability. But as reported, the experimental results did not support the theory predictions. This suggested that there must be other mechanisms also contributing to this phenomenon.

In this section the attempt will be to explain combustor instability in terms of generic system dynamics that also includes the thermo-acoustic coupling with the associated convective time delay. If the dynamic interactions that give rise to a combustor instability can be understood, methodologies could possibly be developed to directly solve this problem either by design of the combustor and its fuel injection or by redesign of the fuel and/or air flow controls.

Most natural processes follow certain generalized dynamic behaviors; For instance electrical filters put in series can generate additional dominant modes contributed by combined reactive elements of individual filters. Two individual mass-spring systems put in series generate nodes, which split on both sides of a separate dominant node and the dominant node changes to an antinode. On the other hand, system source-load impedance effects can take a dominant source and a dominant load mode and completely overshadow them by generating one or more new modes. The later case seems to closely resemble what happens with combustor instabilities. That is where the instability appears at some other frequency than what is predicted by the acoustic mode, and no mode appears at the calculated frequency. Generally, the source-load impedance effect is the result of a more generalized dynamic behavior, whereby, individual components combined to form a system generate new characteristic equations. The new characteristic equation has insufficient gain and phase margin for absolute stability or poor conditional stability properties.

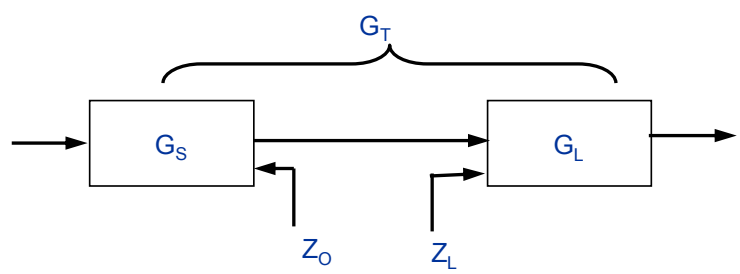

Figure 16 - Source-Load System Impedance Interface

\section{Combustor Source-Load Impedance Interactions}

In this section generalized dynamic relations will be developed for the combustor process in consideration of the system's source-load type dynamic interactions. The purpose of this development is to explain the observed thermo-acoustic coupling that gives rise to combustor instabilities as part of a more general source-load behavior that involves impedances.

As discussed above, systems can exhibit instabilities or oscillatory behavior at frequencies that are not necessarily coincidental to their natural resonance. The combustor process forms a source-load system combination, where fuel and air is transported and controlled into the combustor chamber. This gives rise to certain flow and pressure conditions at the injector exit. Therefore, this part of the system can be thought as the source. Some more mixing is accomplished downstream of the injector and then the fuel-air mixture is burned providing certain flow and pressure conditions at the turbine entrance. This part of the system can be thought as the load. If this is indeed the case the injector (part of the source) can play a significant role in the instability behavior. As discussed above, attempts have been made ${ }^{8}$ to manipulate the convective time delay from the injector to the flame front in order to change the instability behavior based on the time delay theory, but with unpredictable results. In a source-load impedance effect, manipulating the transport delay will affect the phase shift of the load (assuming the source-load interface is formed at the output of the injector). However, in such a relation the undamped resonance formed by the respective characteristic equation is a relation of two frequency dependant variables with magnitudes and phases; that is a combined relation of both the source and the load magnitudes and phases. Therefore, manipulating the phase of say, the load impedance when the actual effect is the combine result of two impedances (magnitudes and phases), is unlikely to produce predictable results.

In any dynamic system where an equivalent sourceload combination is formed, (Figure 16) the overall endto-end system transfer function is 


$$
G_{T}(s)=\frac{G_{S}(s) G_{L}(s)}{1+\frac{Z_{O}(s)}{Z_{L}(s)}}
$$

where $G_{T}(s), G_{S}(s), G_{L}(s)$ are the input-to-output transfer functions of the overall system, the source, and the load, respectively; $Z_{O}(s)$ is the source output impedance and $Z_{L}(s)$ is the load input impedance.

In a test set-up of actual hardware or a physics-based model, impedances could be measured. For example, the pressure-flow ratio could be determined as a function of frequency by injecting a perturbation frequency sweep of flow at the injection point $\left(Z_{O}\right.$ and/or $\left.Z_{L}\right)$ as shown in Figure 16. As perturbation measurement the impedance would be

$$
Z(s)=\frac{\hat{p}(s)}{\hat{\hat{\omega}}(s)}
$$

Injected flow for impedance measurement should be dynamically decoupled such that it doesn't alter the dynamics of the test article. The source output impedance can also be calculated as

$$
Z_{O}(s)=\frac{Z_{P}(s)}{1+L_{C L}(s)}
$$

where $Z_{P}(s)$ and $L_{C L}(s)$ are the open loop output impedance and the closed loop gain respectively. In this case the open loop output impedance will be the impedance without fuel and air flow control. Based on a source-load interface formed on the fuel injector face, Equation 13 will indicate that the injector design or operation can have a significant impact on the instability. However, manipulating the injector to passively suppress the instability is not likely to ensure predictable results, under all conditions, without understanding the mathematical relations of these coupling mechanisms. In turn the open-loop output impedance is

$$
Z_{P}(s)=\left.\frac{\hat{p}_{O}}{\hat{\dot{w}}_{O}}\right|_{\hat{a}_{i}=0}
$$

where $\hat{p}_{O}$ and $\hat{\dot{w}}_{O}$ are the perturbations as functions of frequency at the injector face of the output pressure and the flow respectively, with all other perturbed state variables signified as $\hat{a}_{i}(i=1,2, \ldots . n)$ held to zero. The closed loop gain is

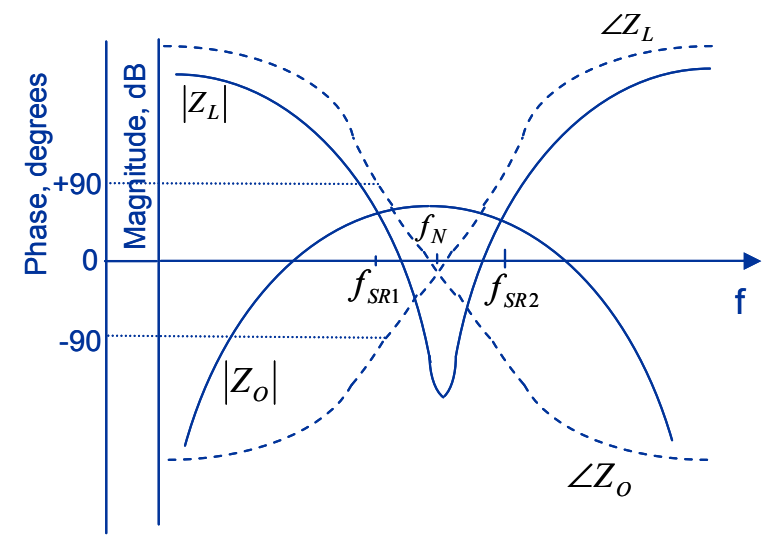

Figure 17 - Bode Plot of Source Load Impedances Showing Stability Margins of the Characteristic Equation

$$
L_{C L}(s)=G_{C}(s) G_{S}(s) H(s)
$$

where $G_{C}(s), G_{S}(s)$ and $H(s)$ are the controller transfer functions, the process or source transfer function in this case and the feedback path transfer function of a typical feedback control system. Examining Equation 15 it can be seen that the closed loop gain $L_{C L}(s)$ can be designed to have a large effect on the output impedance. That would imply that the injected fuel-air ratio controls $\phi$ can be designed (assuming sufficient valve control bandwidth exist) to potentially suppress the instability. However, this would have to be mitigated with dead time transport delays in the control path that would tend to reduce the control bandwidth. Equations 11-15 are generic system dynamic transfer functions applicable to any source-load system, modified here in order to become applicable to fluidic systems. This type of transfer functions and their importance in systems design are better understood in the discipline of Power Electronics. ${ }^{9,10,11}$

It can be seen in Equation 11 that the denominator forms a characteristic equation, which determines the overall stability properties of the system (e.g. based on the Nyquist plot). Therefore, if individually the source or load subsystem exhibits good stability behavior, there is still another stability criterion for the overall system, which depends on the respective source and load impedances. The source stability properties will depend on the gain and phase margins of the closed loop gain $L_{C L}(s)$ in Equation 15. Another important observation from Equation 11 is that frequency domain modeling using super positioning of input-to-output transfer functions without taking into account impedances is valid if and only if $Z_{O}(s) \prec \prec Z_{L}(s)$. For practical purposes it is sufficient when $2 Z_{O}(s) \leq Z_{L}(s)$. In choked 
flows where the static pressure remains constant within a range of flows this inequality constraint is typically met as per Equation 12, where $\hat{p} / \hat{\dot{\omega}} \cong 0$. Thereby, how far the design is into choked flow conditions has a direct effect on the output impedance of the source and consequently on the additional complexity in system dynamics due to impedances. Also, as seen in Equation 13 the output impedance depends on the closed loop gain, and forms another characteristic equation which can also give rise to instability.

The input-to-output transfer functions in Equation 11 can exhibit natural modes like the natural acoustic frequency, discussed previously. Such a mode is likely to show up in the input impedance $Z_{L}$. If the combustor source system was ideal (i.e. $Z_{O}=0$ ) and the acoustic mode was sufficiently undamped, then the combustor would likely exhibit an instability at the frequency of the load or acoustic resonance $f_{N}$, as shown in Figure 17. This would normally match the calculated acoustic frequency. But if the source impedance $Z_{O}$ intersects with the load impedance, as shown in the figure, then the system dominant resonance frequency(s) could shift to the frequency $f_{S R 1}$ and/or $f_{S R 2}$, depending on the stability margins at these frequencies. For instance, Figure 17 presented here for demonstration purposes only, shows that at the frequency $f_{S R 1}$ the phase and gain margins of the system are zero. The phase margin is calculated as $M_{\phi}=180-\left|\angle Z_{O}-\angle Z_{L}\right|$. Therefore, at this frequency a source load system with these characteristics will be completely unstable. As seen from this discussion, a new unstable mode has been generated in this demonstration by the combined source-load system at a frequency where alone neither the source nor the load exhibits any adverse behavior. Even if the mode at the frequency $f_{N}$ is sufficiently damped, instability can still be generated when these system components are integrated to form a system. There are other characteristic equations that could affect system stability as seen in this section and in previous sections. This treatment serves to demonstrate additional possible causes of combustor instability.

The analysis presented in this section suggests that impedances or other characteristic type couplings may be the overall cause responsible for combustor instabilities, which also includes the thermo-acoustic coupling. As discussed above and reported in the literature, there is evidence that would seem to support the idea that there are other additional mechanisms that contribute to combustor instabilities. Based on the analysis presented here the suggested cause of combustor instabilities (including the thermo-acoustic coupling) is impedances. Whether impedance type dynamic interactions play a role in combustor instability can be verified by hardware testing, or possibly by simulation using a physics based model derived from basic principals (i.e. without any impeding assumptions).

\section{CONCLUSIONS}

This paper examines some of the most important characteristics of combustor instabilities based on analysis performed on actual test data of three different combustor configurations, namely, a low frequency combustor rig, a high frequency combustor rig and an actual aero-engine. These analyses were performed with emphasis on control systems design to suppress the instability. The analysis results showed that frequency randomness, amplitude modulation and net random phase walks of the instability are related to the combustor signal-to-noise ratio. Exponential growth of the instability is more of a natural behavior of resonances. Also, evidence of intra-harmonic coupling of instability harmonics was investigated. Further, the effect of noise on combustor instability and its control design was examined as well. Finally, the very cause of combustor instabilities was explored and it seems to be attributed to a more general source-load type impedance interaction that includes the thermo-acoustic coupling.

\section{REFERENCES}

1. Lefebvre, A.H.: Gas Turbine Combustion, $2^{\text {nd }}$ edition, Taylor and Francis, 1999.

2. Lieuwen, C.; Zinn, B.T.: "Investigation of Cycle-toCycle Variability in an Unstable Gas Turbine Combustor, International Gas Turbine \& Aeroengine Congress \& Exhibition, Munich, Germany, 2000.

3. McManus, K.R.; Poinsot, T.; and Candel, S.M.: "A Review of Active Control of Combustion Instabilities," in Progress in Energy and Combustion Science, Volume 19, Issue 1, P. 1-29, February 1993.

4. Cohen, J.M. et al: "Experimental Replication of an Aeroengine Combustion Instability," International Gas Turbine \& Aeroengine Congress \& Exhibition, Munich, Germany, 2000.

5. DeLaat, J.C.; Breisacher, K.J.; Saus, J.R.; Paxson, D.E.: "Active Combustion Control for Aircraft Gas Turbine Engines," $36^{\text {th }}$ Joint Propulsion Conference and Exhibition, Huntsville, AL, 2000.

6. Kopasakis, G.; DeLaat, J.C.: "Adaptive Instability Suppression Controls in a Liquid-Fueled Combustor," AIAA $38^{\text {th }}$ Joint Propulsion Conference and Exhibit, Indianapolis, IN, July 2002, NASA/TM-2002-211805, AIAA-2002-4075. 
7. Kopasakis, G.: "High Frequency Adaptive Instability Suppression Controls in a Liquid-Fueled Combustor," AIAA 39 $9^{\text {th }}$ Joint Propulsion Conference and Exhibit, Huntsville, AL, July 2002, NASA/TM2003-211805, AIAA-2003-9581.

8. Lee J.L.; Kim K.; Santavicca D.A.: "A Study of the Role of Equivalence Ratio Fluctuations During Unstable Combustion in a Lean Premixed Combustor," AIAA $39^{\text {th }}$ Joint Propulsion Conference and Exhibit, Huntsville, AL, July 2002, AIAA-20034015.
9. Middlebrook, R.D.: Topics in Multiple-Loop Regulators and Current-Mode Programming. Proceedings of the IEEE Power Electronics Specialist Conference, NY, NY, 1985.

10. Ridley, R.B.: A New, Continuous-Time Model for Current-Mode Control. Modeling, Analysis, and Design of PWM Converters, Virginia Power Electronics Center, Blacksburg, VA, 1989.

11. Kopasakis, G: Fuzzy Current-Mode Control and Stability Analysis. AIAA $35^{\text {th }}$ IECEC, Las Vegas, Nevada, July 2000. 
Public reporting burden for this collection of information is estimated to average 1 hour per response, including the time for reviewing instructions, searching existing data sources, gathering and maintaining the data needed, and completing and reviewing the collection of information. Send comments regarding this burden estimate or any other aspect of this collection of information, including suggestions for reducing this burden, to Washington Headquarters Services, Directorate for Information Operations and Reports, 1215 Jefferson Davis Highway, Suite 1204, Arlington, VA 22202-4302, and to the Office of Management and Budget, Paperwork Reduction Project (0704-0188), Washington, DC 20503.

\begin{tabular}{|l|l|l}
\hline 1. AGENCY USE ONLY (Leave blank) & $\begin{array}{c}\text { 2. REPORT DATE } \\
\text { February } 2004\end{array}$ & $\begin{array}{r}\text { 3. REPORT TYPE AND DATES COVERED } \\
\text { Technical Memorandum }\end{array}$ \\
\hline
\end{tabular}

4. TITLE AND SUBTITLE 5. FUNDING NUMBERS

Systems Characterization of Combustor Instabilities With Controls Design Emphasis

6. AUTHOR(S)

WBS-22-708-28-09

George Kopasakis

7. PERFORMING ORGANIZATION NAME(S) AND ADDRESS(ES)

National Aeronautics and Space Administration

John H. Glenn Research Center at Lewis Field

Cleveland, Ohio 44135-3191
8. PERFORMING ORGANIZATION REPORT NUMBER

E-14345

\section{SPONSORING/MONITORING AGENCY NAME(S) AND ADDRESS(ES)}

National Aeronautics and Space Administration

Washington, DC 20546-0001
10. SPONSORING/MONITORING AGENCY REPORT NUMBER

NASA TM-2004-212912

AIAA-2004-0638

\section{SUPPLEMENTARY NOTES}

Prepared for the 42nd Aerospace Sciences Meeting and Exhibit sponsored by the American Institute of Aeronautics and Astronautics, Reno, Nevada, January 5-8, 2004. Responsible person, George Kopasakis, organization code 5530, 216-433-5327.

12a. DISTRIBUTION/AVAILABILITY STATEMENT 12b. DISTRIBUTION CODE

Unclassified - Unlimited

Subject Categories: 01, 02, 07, and 08

Distribution: Nonstandard

Available electronically at http://gltrs.grc.nasa.gov

This publication is available from the NASA Center for AeroSpace Information, 301-621-0390.

\section{ABSTRACT (Maximum 200 words)}

This effort performed test data analysis in order to characterize the general behavior of combustor instabilities with emphasis on controls design. The analysis is performed on data obtained from two configurations of a laboratory combustor rig and from a developmental aero-engine combustor. The study has characterized several dynamic behaviors associated with combustor instabilities. These are: frequency and phase randomness, amplitude modulations, net random phase walks, random noise, exponential growth and intra-harmonic couplings. Finally, the very cause of combustor instabilities was explored and it could be attributed to a more general source-load type impedance interaction that includes the thermo-acoustic coupling. Performing these characterizations on different combustors allows for more accurate identification of the cause of these phenomena and their effect on instability.

\section{SUBJECT TERMS}

Active combustion control; Combustion stability; Combustion instability; Thermoacoustic instability; Acoustic instability; Combustion dynamics; Aero-engine control instability characterization; Lean combustion; Lean burning; Low-emission combustors

\begin{tabular}{|c|c|c|}
\hline $\begin{array}{c}\text { 17. SECURITY CLASSIFICATION } \\
\text { OF REPORT } \\
\text { Unclassified }\end{array}$ & $\begin{array}{c}\text { 18. SECURITY CLASSIFICATION } \\
\text { OF THIS PAGE } \\
\text { Unclassified }\end{array}$ & $\begin{array}{c}\text { 19. SECURITY CLASSIFICATION } \\
\text { OF ABSTRACT } \\
\text { Unclassified }\end{array}$ \\
\hline
\end{tabular}

15. NUMBER OF PAGES

18

16. PRICE CODE

20. LIMITATION OF ABSTRACT 